OPEN ACCESS

Edited by:

Shokrollah Elahi,

University of Alberta, Canada

Reviewed by: Namal P. M. Liyanage, National Cancer Institute, USA

Paul Urquhart Cameron, University of Melbourne, Australia

*Correspondence:

Abdul W. Ansar

wahid.ansari@gmail.com

these authors have contributed equally to this work.

Specialty section: This article was submitted to HIV and AIDS,

a section of the journal

Frontiers in Immunology

Received: 14 December 2016 Accepted: 09 March 2017

Published: 27 March 2017

Citation: Ahmad F, Shankar EM, Yong YK, Tan HY, Ahrenstorf G, Jacobs R, Larsson $M$, Schmidt RE Kamarulzaman A and Ansari AW (2017) Negative Checkpoint Regulatory Molecule 2B4 (CD244)

Upregulation Is Associated with Invariant Natural Killer T Cell Alterations and Human Immunodeficiency Virus Disease Progression.

Front. Immunol. 8:338. doi: 10.3389/fimmu.2017.00338

\section{Negative Checkpoint Regulatory Molecule 2B4 (CD244) Upregulation Is Associated with Invariant Natural Killer T Cell Alterations and Human Immunodeficiency Virus Disease Progression}

\author{
Fareed Ahmad'1t, Esaki M. Shankar ${ }^{2,3,4 t}$, Yean K. Yong'2, Hong Y. Tan'2, Gerrit Ahrenstorf', \\ Roland Jacobs ${ }^{1}$, Marie Larsson ${ }^{5}$, Reinhold E. Schmidt ${ }^{1}$, Adeeba Kamarulzaman ${ }^{2,6}$ and \\ Abdul W. Ansari2,6*

\begin{abstract}
Department of Clinical Immunology and Rheumatology, Hannover Medical School, Hannover, Germany, ${ }^{2}$ Centre of Excellence for Research in AIDS (CERiA), University of Malaya, Kuala Lumpur, Malaysia, ${ }^{3}$ Department of Medical Microbiology, University of Malaya, Kuala Lumpur, Malaysia, ${ }^{4}$ Division of Infection Biology, Department of Life Sciences, School of Basic \& Applied Sciences, Central University of Tamil Nadu (CUTN), Thiruvarur, India, ${ }^{5}$ Division of Molecular Virology, Department of Clinical and Experimental Medicine, Linkoping University, Linkoping, Sweden, ${ }^{6}$ Department of Medicine, University of Malaya, Kuala Lumpur, Malaysia
\end{abstract}

The CD1d-restricted invariant natural killer T (iNKT) cells are implicated in innate immune responses against human immunodeficiency virus (HIV). However, the determinants of cellular dysfunction across the iNKT cells subsets are seldom defined in HIV disease. Herein, we provide evidence for the involvement of the negative checkpoint regulator (NCR) 2B4 in iNKT cell alteration in a well-defined cohort of HIV-seropositive antiretroviral therapy (ART) naïve, ART-treated, and elite controllers (ECs). We report on exaggerated 2B4 expression on iNKT cells of HIV-infected treatment-naïve individuals. In sharp contrast to CD4-iNKT cells, 2B4 expression was significantly higher on CD4+ iNKT cell subset. Notably, an increased level of 2B4 on iNKT cells was strongly correlated with parameters associated with HIV disease progression. Further, iNKT cells from ARTnaïve individuals were defective in their ability to produce intracellular IFN- $\gamma$. Together, our results suggest that the levels of 2B4 expression and the downstream co-inhibitory signaling events may contribute to impaired iNKT cell responses.

Keywords: invariant natural killer T cells, 2B4, human immunodeficiency virus, inhibitory, IFN- $\gamma$, CD4

\section{INTRODUCTION}

Invariant natural killer $\mathrm{T}$ (iNKT) cells are a unique subset of $\mathrm{T}$ lymphocyte that bridges innate and adaptive immune responses (1). In addition to immune regulation, iNKT cell role is also implicated in several viral infections (2). In human peripheral blood, iNKT cells constitute a smaller fraction ranging between 0.01 and $>1 \%$ of the total $\mathrm{CD}^{+} \mathrm{T}$ cells $(3,4)$. iNKT cells express invariant TCR V $\alpha 24$ and V $\beta 11$ chain, and NK cell markers such as CD161 and NKG2D (1). Unlike the classical T and B cells, iNKT cells recognize only glycolipid and phospholipid antigens of microbes presented on 
CD1d, a non-polymorphic major histocompatibility complex class I (MHC class I)-like molecule (5). Upon activation, iNKT cells rapidly produce large amounts of both IFN- $\gamma$ (Th1) and IL-4 (Th2) cytokines to regulate host immune responses. Functionally, iNKT cells can be classified into CD4- (Th1cytokine-expressing) and $\mathrm{CD}^{+}$(Th1 and Th2 cytokine-producing) subsets. The $\mathrm{CD}^{-}{ }^{-} \mathrm{iNKT}$ cells can further be divided into $\mathrm{CD}^{+}$as well as $\mathrm{CD}^{-} \mathrm{CD}^{-}$(double negative-DN) populations. $\mathrm{CD}^{+}{ }^{+} \mathrm{iNKT}$ cell predominantly exhibits a Th1 phenotype. Evidence suggests that $\mathrm{CD}^{+}$and $\mathrm{CD}^{-}{ }^{-}$iNKT cell homeostasis significantly impact the functional outcome of immune responses in the host $(6,7)$.

Negative checkpoint regulators (NCRs) such as cytolytic Tlymphocyte-associated antigen-4 (CTLA-4), T-cell immunoglobulin mucin-3 (TIM-3), programmed death-1 (PD-1), 2 B4 (CD244), lymphocyte activation gene-4 (LAG-3), and CD160 play a critical role in the regulation of anti-viral $\mathrm{CD}^{+} \mathrm{T}$ cell responses during human immunodeficiency virus (HIV) infection (8). Persistent antigen exposure and immune activation during chronic HIV infection lead to the upregulation of these molecules, initiating $\mathrm{CD}^{+} \mathrm{T}$ cell exhaustion and functional immune impairment $(9,10)$. The initiation of anti-retroviral therapy (ART) has been shown to dampen the expression of some of the regulatory molecules to normal levels $(11,12)$. In a latest development, NCRs such as PD-1, the T cell immune receptor with Ig and ITIM domains (TIGIT) and LAG-3 have been proposed to harness HIV persistence (13). Akin to that in $\mathrm{CD}^{+} \mathrm{T}$ cells, some of the NCRs have also been shown to suppress iNKT cell functions. For instance, upregulation of PD-1 on iNKT cells of ART-naïve individuals is associated with poor cell function (14). The NK cell receptor 2B4 belongs to the signaling lymphocyte activation molecule (SLAM) family of proteins that binds to a high-affinity ligand CD48 (15) and transduces signal via immune receptor tyrosin-based switch motif (ITSM) (16). 2B4 has previously been shown to regulate both $\mathrm{T}$ and NK cell anti-viral responses (17). Earlier studies have hinted that $2 \mathrm{~B} 4$ could enhance $\mathrm{NK}$ and $\mathrm{CD}^{+} \mathrm{T}$ cell functions (18), and recent lines of evidence suggest that $2 \mathrm{~B} 4$ may possess both co-stimulatory as well as co-inhibitory functions (19). For instance, a relatively low expression of 2B4 on NK cells has been shown to trigger their proliferation and eventual release of IFN- $\gamma$, while a higher expression resulted in functional suppression of $\mathrm{HCV}$-specific $\mathrm{CD}^{+} \mathrm{T}$ cells (20).

Several studies have shown the depletion of iNKT cells, in particular, the $\mathrm{CD}^{+}$subset of these cells from the peripheral circulation of HIV-infected individuals (21-24). The primary cause of such depletion is reportedly attributed to the expression of HIV co-receptors, CCR5 and/or CXCR4 on iNKT cells (21, $22,25)$. Of the iNKT cell subsets, the $\mathrm{CD} 4^{+}$appears to be highly susceptible to HIV infection $(21,23)$. In addition, iNKT cells have also been found to be defective in their ability to produce IFN- $\gamma$ in HIV disease $(14,26,27)$. Interestingly, ART follow-up studies have shown slow and poor recovery of iNKT cells although the data were insignificant during the first year of treatment $(28,29)$.

In contrast to the relatively commonly studied NCRs PD-1, TIM-3, and LAG-3, far less is known about the contribution of 2B4 in iNKT cell regulation in HIV disease. Here, we compared the surface levels of 2B4 expression and the associated cellular dysfunction in a well-defined cohort of HIV-seropositive
ART-naïve, ART-treated, and elite controllers (ECs). We also provided evidence of elevated levels of 2B4 on the iNKT cells of ART-naïve individuals. Of the iNKT subsets, 2B4 expression was significantly higher on $\mathrm{CD}^{+}$as compared to the $\mathrm{CD} 4^{-}$subset. Further, iNKT cells were defective in their ability to produce IFN- $\gamma$ and there was a positive correlation between $2 \mathrm{~B} 4^{+}$iNKT cells and HIV disease progression. These data advance our understanding of iNKT cell regulation during virus insult.

\section{MATERIALS AND METHODS}

\section{Human Subjects}

A total of $48 \mathrm{HIV}$-infected individuals including HIV-seropositive (ART-naïve, $n=23$ ), combination ART-treated (cART, $n=19$ ), and elite controllers (ECs, $n=6$ ), and HIV-seronegative healthy controls (HCs, $\mathrm{n}=15$ ) were recruited into the study. Naïve individuals never received ART while treated individuals were on ART for at least one year. The ART regimens comprised three or four of the following: tenofovir, emtricitaine, nevirapine, retrovir, atazanavir, ritonavir, abacavir, zidofovir, saquinavir, fosamprenavir, lopinavir, lamivudine, efavirenz, and darunavir. A summary of clinical features of all participants is described in Table $\mathbf{1}$. Written informed consents were taken from each participant and the study was approved by the Institutional Ethics Committee (MEC) and the Institutional Review Board (IRB) of the University of Malaya Medical Center (UMMC), Kuala Lumpur, Malaysia and the Hannover Medical School, Germany, respectively.

\section{Peripheral Blood Mononuclear Cells (PBMCs) and Immunophenotyping}

Peripheral blood mononuclear cells were isolated as described before $(30,31)$ and stored in liquid nitrogen until use. Briefly, freshly drawn intravenous blood was subjected to ficoll-hypaque gradient centrifugation. 1-2 $\times 10^{6} \mathrm{PBMCs}$ were first stained with fixable viability dye eFluor 506 (eBiosciences) in order to exclude dead cells from the sample. APC-conjugated PBS-57-loaded CD1d tetramer (NIH Tetramer Core Facility, National Institute of Health, Atlanta, GA, USA) and a panel of following antibodies were purchased from BioLegends; PECy7-CD3, APC-Cy7-CD3, Pacific Blue-CD4, PerCP Cy5.5-CD8, FITC-2B4. Fluorescenceminus-one (FMO) stain was included to avoid false-positive signals. Cells were acquired on a BD FACSCanto II flow cytometer using FACS Diva software (v.7), and analyzed by FlowJo software (v.8.4.4, Tree Star).

\section{Cell Stimulation and Intracellular IFN- $\gamma$ Cytokine Detection}

Briefly $2-3 \times 10^{6}$ cells were stimulated with $100 \mathrm{ng} / \mathrm{ml}$ alphagalactosylceramide ( $\alpha$-GalCer, kindly provided by Dr. Paul Savage, Brigham Young University, UT, USA) in a 24-well culture plate. After $1 \mathrm{~h}$ of stimulation, brefeldin-A $(10 \mu \mathrm{g} / \mathrm{ml})$ was added and cultured for another $5 \mathrm{~h}$. Cells were harvested and washed twice with phosphate buffer saline (PBS) before staining with fixable viability dye eFluor 506 exclude dead cell. Cells were then surface stained with CD3, CD1d tetramer followed by fixation, and permeabilization using Fix/Perm kit (BD biosciences kit) as 
TABLE 1 | Clinicodemographic characteristics of study participants.

\begin{tabular}{|c|c|c|c|c|c|c|c|}
\hline \multirow[t]{2}{*}{ Group } & \multirow{2}{*}{$\begin{array}{c}\text { Numbers } \\
(n)\end{array}$} & \multirow{2}{*}{$\begin{array}{c}\text { Age-years } \\
\text { (median) }\end{array}$} & \multicolumn{2}{|c|}{ Sex } & \multirow{2}{*}{$\begin{array}{l}\text { CD4 count } \\
\text { (SEM) }\end{array}$} & \multirow{2}{*}{$\begin{array}{c}\text { Viral load } \\
\text { (median) }\end{array}$} & \multirow{2}{*}{$\begin{array}{c}\text { CD4/CD8 } \\
\text { (SEM) }\end{array}$} \\
\hline & & & $\mathbf{M}$ & $\mathbf{F}$ & & & \\
\hline $\mathrm{HC}$ & 15 & 39 & 10 & 5 & NA & NA & NA \\
\hline Naïve & 23 & 38 & 16 & 7 & $330 \pm 43.4$ & $67,700 \pm 65,935$ & $0.370 \pm 0.042$ \\
\hline ART & 19 & 53 & 12 & 7 & $528 \pm 59.7$ & ND & $0.670 \pm 0.052$ \\
\hline EC & 6 & 54 & 4 & 2 & $1,066 \pm 134$ & $33 \pm 59.7$ & $0.99 \pm 0.128$ \\
\hline
\end{tabular}

CD4 count and CD4/CD8 ratio represented as mean \pm SEM while viral load as median \pm SEM.

$A R T$, anti-retroviral treated; EC, elite controllers; F, female; HC, healthy controls; Naïve, HIV untreated; M, male; NA, not available; ND, not detected.

described before (32). Pacific Blue-IFN- $\gamma$ antibody (BioLegends) was added to detect intracellular expression. Cells were washed before acquisition by flow cytometer.

\section{Statistical Analyses}

For statistical evaluation of data, we have used GraphPad PRISM (v.5.0) software. Unpaired, two-tailed $t$-test was used to compare between two groups or one-way ANOVA followed by Tukey test was used for comparing more than two groups. To determine correlation, Pearson analysis was employed. $P$ values of $<0.05$ were considered significant.

\section{RESULTS}

\section{CD4+ iNKT Cell Subset Was Preferentially Lost from the Circulation of HIV-Positive Treatment-Naïve Patients, and ART Failed to Restore CD4 ${ }^{+}$iNKT Cell Frequency}

To investigate the size of iNKT cell pool in the peripheral blood of different study groups, we employed a flow cytometric approach using iNKT cell-specific PBS 57-loaded/CD1d tetramer and anti-CD3 antibody (Figure 1A). Taking into consideration the scarcity of iNKT cells in peripheral blood, we applied a stringent gating strategy during cell acquisition and data analysis (Figure S1 in Supplementary Material). Fluorescence-minus-one (FMO) staining was used to determine the threshold values for expression of the specific markers. Consistent with previous reports $(23,33)$, a substantial loss of iNKT cells was observed in ARTnaïve individuals (mean $0.04 \pm 0.009 \%, P=0.008$ ) in comparison with healthy controls (HCs) (mean $0.16 \pm 0.048 \%$ ) (Figure 1C). Interestingly, the frequency in ART subjects remained low (mean $0.04 \pm 0.012 \%, P=0.017$ ) in relation to HCs. Notably, the initiation of ART regimens was unable to completely reconstitute iNKT cell numbers. However, the frequency of iNKT cells in ECs (mean $0.06 \pm 0.037 \%$ ) was more or less similar as HCs $(P=0.502)$. The data from EC cohort suggest that in addition to infection of iNKT cells by HIV, on-going HIV replication may act as an additional factor contributing significantly to iNKT cell depletion from peripheral blood.

As described, iNKT cells can be broadly divided into CD4 ${ }^{-}$ and $\mathrm{CD} 4^{+}$subsets (6), hence we sought to examine the frequency of these two subsets during HIV infection. We labeled the cells with CD1d tetramer, anti-CD3, and anti-CD4 antibodies and analyzed it through flow cytometry (Figure 1B). We observed severe depletion of $\mathrm{CD}^{+}{ }^{+}$iNKT cell subset in ART-naive subjects (mean $11.13 \pm 1.65 \%, P=0.0001$ ) (Figure 1D). This could probably be due to HIV infection and subsequent loss of $\mathrm{CD}^{+}$ iNKT cells. Interestingly, the cell frequency remained lower in the ART cohort (mean $16.11 \pm 3.12 \%, P=0.001$ ) compared to HCs (mean $37.47 \pm 5.51 \%$ ), suggestive of the lack of appreciable reconstitution of $\mathrm{CD}^{+}{ }^{+} \mathrm{iNKT}$ cells despite receiving ART. Nonetheless, the $\mathrm{CD}^{+}{ }^{+}$iNKT cell distribution in ECs was more or less similar to that seen in HCs $(P=0.549)$.

Next, we sought to estimate the $\mathrm{CD}^{-}{ }^{-} \mathrm{iNKT}$ cell subset (Figure 1B). Interestingly, there was a marked increase in the cell frequency among ART-naïve (mean $88.60 \pm 1.66 \%, P=0.0001$ ) individuals as compared to HCs (mean 62.51 $\pm 5.49 \%$ ) (Figure 1E). However, we did not observe any significant impact in the ART patient group as frequency of $\mathrm{CD}^{-}{ }^{-} \mathrm{iNKT}$ cell continued to remain higher. Appearance of relatively higher CD4-iNKT cells is believed to be mainly contributed by $\mathrm{CD}^{+}$iNKT cells (33).

\section{Expression of 2B4 Was Significantly Upregulated on Bulk of CD3 ${ }^{+} \mathrm{T}$ Cells of ART-Naïve Individuals}

Given that a complex network of co-stimulatory and co-inhibitory molecules regulate $\mathrm{T}$ cell immune responses (8), and that differential expression of some of the well characterized molecules (PD-1, CD160, TIM-3, LAG-3, and 2B4) has already been shown to severely affect antigen-specific $\mathrm{CD}^{+} \mathrm{T}$-cell responses, especially in HIV and HCV $(10,34-36)$ infections, their expression on iNKT cells of chronic viral diseases are yet to be investigated. Given the suppressive role of $2 \mathrm{~B} 4$ in $\mathrm{HIV}$-specific $\mathrm{CD} 8^{+} \mathrm{T}$ cells (10), we examined the levels of $2 \mathrm{~B} 4$ expression on $\mathrm{T}$ cell subsets including $\mathrm{CD}^{+}, \mathrm{CD}^{+}$, and $\mathrm{CD}^{+} \mathrm{T}$ cells (Figure $2 \mathrm{~A}$ ). The expression of $2 \mathrm{~B} 4$ was markedly increased on bulk $\mathrm{CD}^{+} \mathrm{T}$ cells of ART-naïve (mean $42.23 \pm 4.06 \%, P=0.0009$ ), and relatively less significantly in ART-treated individuals (mean $34.56 \pm 5.58 \%, P=0.041$ ) as compared to HCs (mean 18.91 $\pm 3.89 \%$ ) (Figure 2B). However, the differences of $2 \mathrm{~B} 4$ were not significant between ART-treated and treatment-naïve individuals $(P=0.27)$, whereas ECs showed comparable expression pattern with respect to HCs.

Next, we sought to examine the level of 2B4 expression on $\mathrm{CD} 4^{+} \mathrm{T}$ cells. We observed very low $2 \mathrm{~B} 4$ expression as compared to bulk $\mathrm{CD}^{+}$and $\mathrm{CD}^{+} \mathrm{T}$ cells. Further, there was no significant difference when both ART-naïve and ART subjects were compared with $\mathrm{HCs}$, despite an apparent increase in 2B4 expression across both the study groups (Figure $2 \mathrm{C}$ ). These data strongly suggest an induction of $2 \mathrm{~B} 4$ on $\mathrm{T}$ cells during HIV infection. In contrast 
A

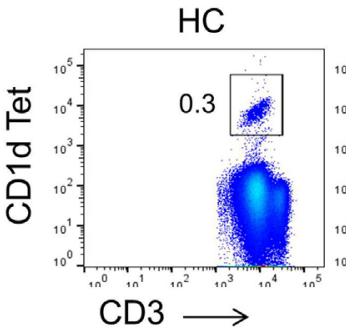

B

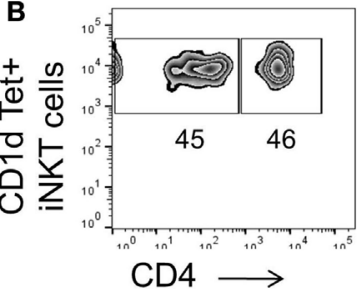

C

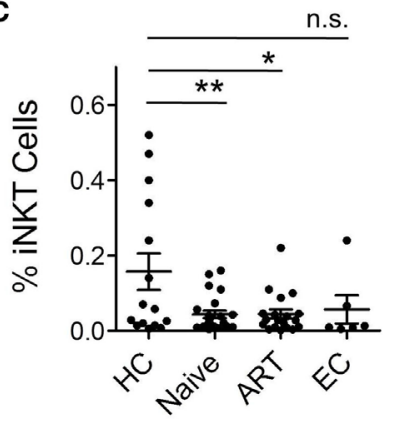

Naive
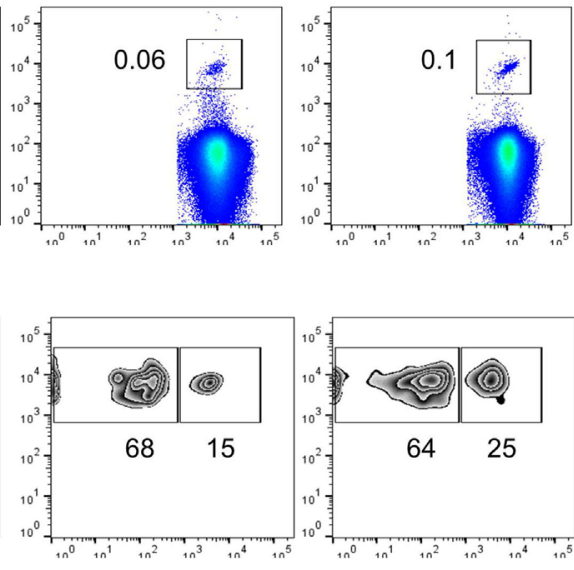

ART

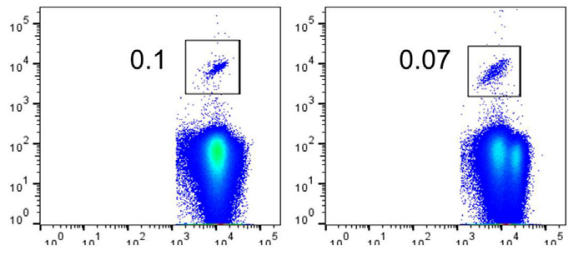

EC
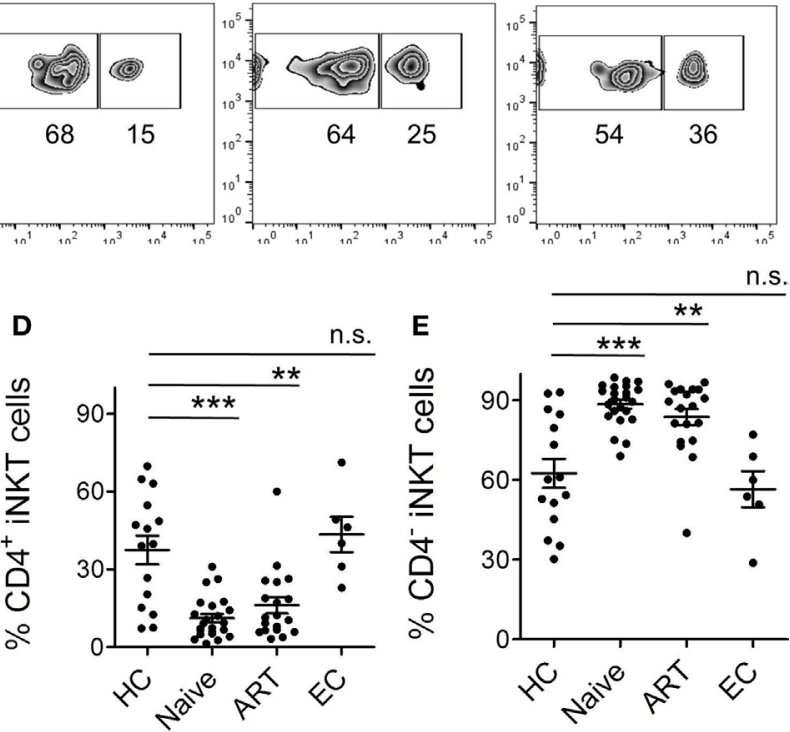

FIGURE 1 | Frequency of CD1d-restricted invariant natural killer T (iNKT) cells and their subsets. Frozen peripheral blood mononuclear cells (PBMCs) from healthy controls (HCs, $n=15$ ), human immunodeficiency virus-seropositive (ART-naiive, $n=23$ ), ART-treated (ART, $n=19$ ), and elite controllers (ECs, $n=6$ ) were stained with PBS-57 loaded/CD1d tetramer, anti-CD3, and anti-CD4 antibodies before acquisition by flow cytometer. A detailed gating strategy is described in Figure S1 in Supplementary Material. (A) Representative FACS plot from an individual of each cohort, numbers indicate percent CD1d Tet ${ }^{+}$iNKT cells.

(B) Representative plot showing percent of $\mathrm{CD}^{+}$and $\mathrm{CD}^{-}$sub-population within the $\mathrm{CD} 1 \mathrm{~d}$ tet ${ }^{+}$iNKT cell-gated population. (C) Scatter plot showing a summary of CD1d tet ${ }^{+}$iNKT cells frequency across the various study cohorts. (D) Frequency of CD4+ ${ }^{+}$NKT cells and CD4-iNKT cells $(E)$ in various cohorts. ${ }^{*} P<0.05$,

${ }^{* *} P<0.01,{ }^{* \star *} P<0.001$, and n.s. stands for non-significant.

to $\mathrm{CD} 4^{+} \mathrm{T}$ cells, $\mathrm{CD} 8^{+} \mathrm{T}$ cells displayed significantly higher levels of 2B4 in ART naïve (mean $60.95 \pm 5.11 \%, P=0.01$ ) as compared to HCs (mean $37.34 \pm 8.55 \%$ ) (Figure 2D). Furthermore, individuals who received ART exhibited significantly lower 2B4 (mean $44.13 \pm 6.02 \%, P=0.041$ ) levels as compared to ART-naïve subjects. Our observations are in line with previous findings where $2 \mathrm{~B} 4$ expressions on virus-specific $\mathrm{CD}^{+} \mathrm{T}$ cells declined to normal levels following the initiation of ART $(10,20)$. In general, the basal levels of $2 \mathrm{~B} 4$ expression on $\mathrm{CD} 4^{+}$cells appeared to be lower than $\mathrm{CD}^{+} \mathrm{T}$ cells (Figure S2A in Supplementary Material).

\section{B4 Expression Was Higher in Treatment- Naïve Individuals and ART Initiation Failed to Normalize 2B4 Levels on iNKT Cell Subsets}

Experimental evidence suggests that 2B4 levels were elevated on CD4, CD8, and NK cells during chronic HCV and HIV $(10,20)$ infections. Nonetheless, the expression of $2 \mathrm{~B} 4$ on iNKT cells has seldom been investigated. Here, we endeavored to investigate 2B4 expression using flow cytometry across the study groups. We found significantly higher levels of 2B4 expression in ART-naïve individuals as compared to HCs, ART and ECs (Figure 3A). The expression was $\sim 2$-fold higher in ART-naïve (mean $61.30 \pm 4.13 \%$, $P=0.0003$ ) than HCs (mean $34.10 \pm 5.34 \%$ ) (Figure 3B). The ART-treated subjects showed significantly lower 2B4 levels (mean $46.47 \pm 5.70 \%, P=0.037$ ) as compared to ART naïve indicating that treatment initiation led to marked downregulation of $2 \mathrm{~B} 4$ expression. On the other hand, ECs with apparently suppressed HIV replication, exhibited more or less similar levels of 2B4 as compared to HCs.

Next, we determined to examine the expression of $2 \mathrm{~B} 4$ on the different iNKT cell subsets (Figure 3A). CD4 ${ }^{+}$cells of ART-naïve individuals showed significantly higher 2B4 expression (mean $28.48 \pm 3.24 \%, P=0.013$ ) relative to HCs (mean $14.94 .34 \pm 4.08 \%$ ) (Figure 3C). Of note, ECs exhibited significantly lower levels of 2B4 as compared to ART-naive $(P=0.007)$ subjects suggesting that lack of HIV replication failed to induce $2 \mathrm{~B} 4$ expression on 

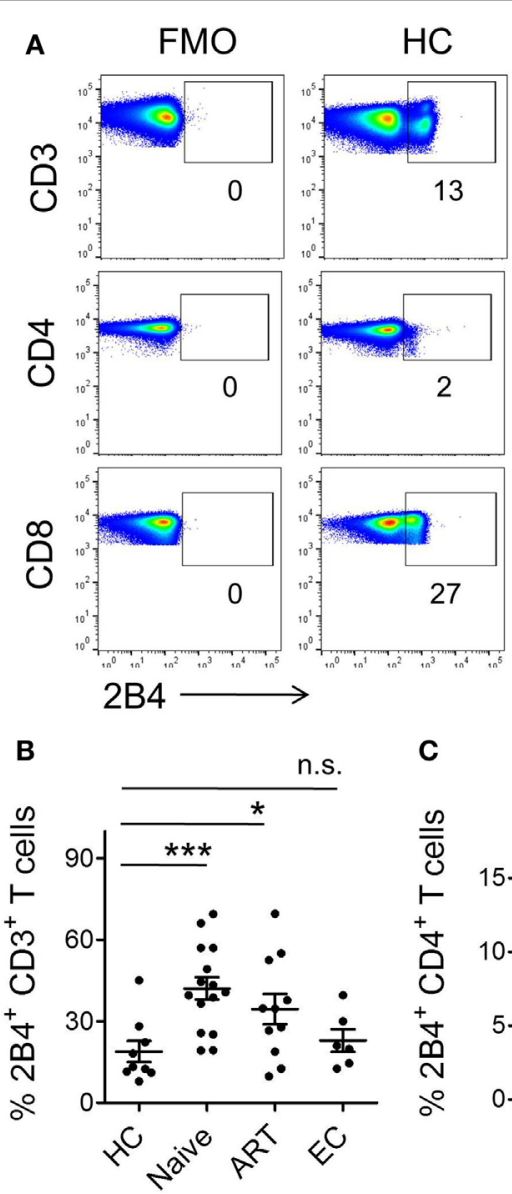
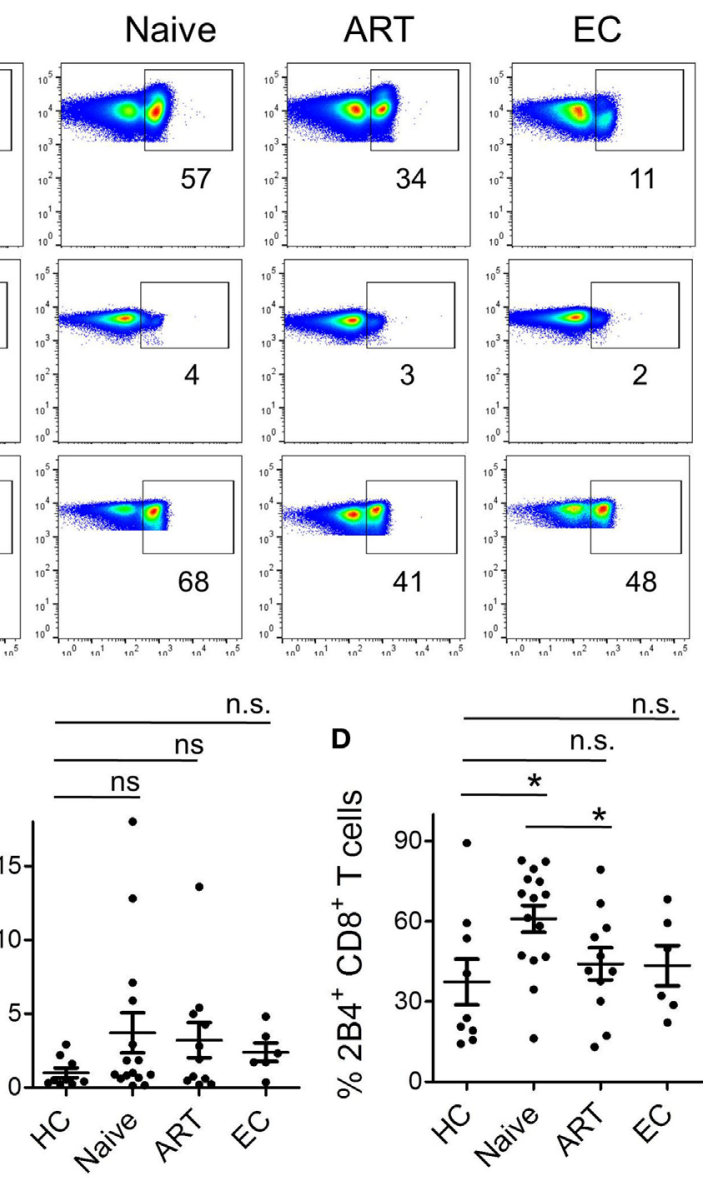

FIGURE 2 | Expression pattern of 2B4 molecule on CD3, CD4, and CD8 T cells. (A) Representative FACS plots showing percent 2B4 expression on total CD3 (upper panel), CD4 (middle panel), and CD8 (lower panel) from different cohorts. Fluorescence-minus-one (FMO) staining was used to determine the threshold values for the expression of specific markers. (B) Scatter plot showing the mean percentage $2 \mathrm{~B} 4$ expression on $\mathrm{CD} 3^{+} \mathrm{T}$ cells of various cohorts, HCs ( $n=9$ ), ART naïve $(n=15)$, ART $(n=11)$, and ECs $(n=6)$; whereas $(\mathbf{C}, \mathbf{D})$ represent the mean percentage of $2 \mathrm{~B} 4$ expression levels on CD4 ${ }^{+}$and CD8 ${ }^{+} \mathrm{T}$ cells, respectively. ${ }^{\star} P<0.05,{ }^{\star \star *} P<0.001$, and n.s. stands for non-significant value.

CD4 ${ }^{+}$iNKT cell subsets from ECs. However, we did not observe any apparent decrease in 2B4 in ART-treated individuals, suggesting that treatment initiation seldom had any effect on 2B4 expression. Although there was an increase in 2B4 in ART-naïve and ART-treated individuals as compared to HCs, this, however, failed to reach a significant value (Figure $3 \mathrm{D}$ ). It should be noted that the baseline 2B4 expression on $\mathrm{CD} 44^{-}$iNKT cells was always greater than that of the $\mathrm{CD}^{+}$subsets (Figure S2B in Supplementary Material). Together, our data suggest that HIV infection leads to the induction of $2 \mathrm{~B} 4$ on bulk $\mathrm{T}$ cells as well as on their subsets, especially the $\mathrm{CD} 4^{+}$iNKT cells.

\section{Expression of 2B4 on iNKT Cells Inversely Correlated with Intracellular Production of IFN- $\gamma$}

Rapid production of large amounts of IFN- $\gamma$ is the hallmark of activated iNKT cells. Hence, we assessed the ex vivo ability of peripheral iNKT cells to produce IFN- $\gamma$ post $\alpha$-GalCer stimulation. We performed intracellular IFN- $\gamma$ cytokine staining of PBMCs obtained from the various study groups. After surface staining, cells were permeabilized and subsequently labeled with anti-IFN- $\gamma$ antibody. Cells were gated on $\mathrm{CD}^{+} \mathrm{CD} 1 \mathrm{~d}$-tetramer ${ }^{+}$ population and investigated for IFN- $\gamma$ production (Figure 4A). As compared to $\mathrm{HCs}$ (mean $34.23 \pm 7.12 \%$ ), we observed $\sim 2$-fold lower production of IFN- $\gamma$ by iNKT cells of ART-naïve individuals ( $n=15$, mean $15.74 \pm 2.33 \%, P=0.0069)$ (Figure 4B). ART-treated individuals, despite the on-going residual immune reconstitution, failed to produce optimal levels of intracellular IFN- $\gamma$.

Next, to understand the impact of increased levels of 2B4 on intracellular IFN- $\gamma$ production, we surface-stained the cells for 2B4 and performed standard 6-h stimulation experiments. However, we were unable to detect 2B4 surface expression during cell acquisition, which most likely could be due to the downregulation of 2B4 after $\alpha$-GalCer stimulation as shown previously in the case of $\mathrm{CD}^{+} \mathrm{T}$ cells, where a similar observation ensued following antigenic stimulation (37). Therefore, in an attempt to 


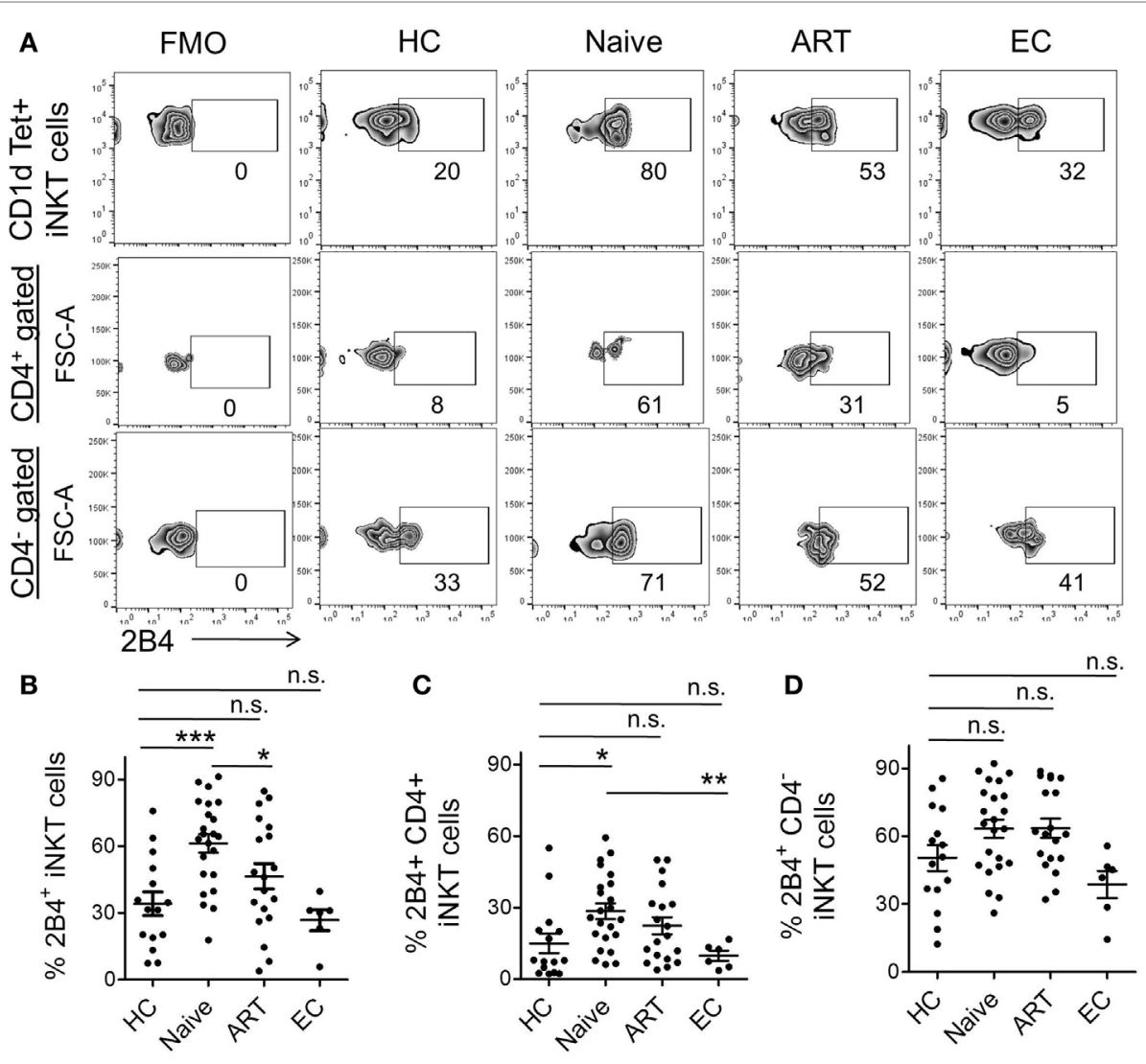

FIGURE 3 | Expression levels of 2B4 on invariant natural killer T (iNKT) cells and their subsets. (A) Representative zebra plot showing percent 2B4 expression on iNKT cells of representative individuals from various cohorts. iNKT cells (PBS-57 loaded/CD1d-tetramer+ CD3+) gated population was looked for surface 2B4 levels (upper panel). While 2B4 expression on CD4+ (middle panel) and CD4-iNKT cell subset (lower panel) were first gated on CD4+ and CD4population then presented with FSC-A (Y-axis). (B) Scatter plot showing the mean percentage of 2B4 levels on bulk iNKT cells of HCs $(n=15)$, ART naïve $(n=23)$, ART $(n=19)$, and ECs $(n=6)$. Mean percentage of 2B4 levels on CD4+ $(\mathbf{C})$ and CD4-iNKT cell subsets (D). Fluorescence-minus-one (FMO) was taken to exclude false-positive values for $2 \mathrm{~B} 4$. ${ }^{\star} P<0.05$, ${ }^{\star \star \star} P<0.001$, and n.s. stands for non-significant value.

understand the potential relationship between $2 \mathrm{~B}^{+}$and IFN $-\gamma^{+}$ iNKT cells, we performed a correlation analysis. Interestingly, we observed a significant inverse correlation $(r=-0.577, P=0.030$, Figure 4C). These data indirectly indicate the association between the levels of 2B4 and iNKT cell functionality.

\section{Higher Expression of 2B4 on iNKT Cells Correlated with HIV Disease Progression}

In order to understand the relevance of $2 \mathrm{~B} 4$ expression on iNKT cells with HIV disease, a correlation analysis was performed between $2 \mathrm{~B} 4^{+}$iNKT cells of ART-naïve cohort and known clinical parameters of HIV disease progression such as viral load, CD4 count, and $\mathrm{CD} 4 / \mathrm{CD} 8$ ratio. We found a positive correlation ( $r=0.434, P=0.038$ ) between $2 \mathrm{~B} 4^{+}$iNKT cell frequency and the viral load (Figure 5A). Similar analyses were performed with CD4 counts and CD4/CD8 ratio. Notably, we observed an inverse correlation $(r=-0.430, P=0.040)$ between $2 \mathrm{~B} 4^{+}$iNKT cells and CD4 counts (Figure 5B), and CD4/CD8 ratio $(r=-448$, $P=0.031$ ) (Figure 5C). Taken together, our data suggest that high levels of 2B4 expression could likely determine the functionality of iNKT cells in HIV infection.

\section{DISCUSSION}

Negative checkpoint regulators, also known as negative regulatory molecules, play a key role in shaping T-cell immune responses against chronic viral infections. A vast majority of previous studies are based on molecules expressed by virus-specific $\mathrm{CD}^{+}$ $\mathrm{T}$ cells both in vivo (36) and in vitro $(34,35,38)$. However, a similar observation is lacking for innate lymphocytes, such as iNKT cells. Here, we report for the first time, the relationship between the levels of 2B4, a co-inhibitory molecule, and their impact on iNKT cell dysfunction in HIV infection. Using a large cohort of HIV-seropositive ART-naïve, ART-treated, and ECs, we examined the phenotypic and functional alterations across the peripheral iNKT cell compartment. Here, we observed an upregulation of 2B4 on CD1d-restricted iNKT cells of ARTnaïve individuals. Among the iNKT cell subsets, $\mathrm{CD} 4^{+}$expressed significantly higher $2 \mathrm{~B} 4$ levels as compared to the $\mathrm{CD}^{-}$phenotypes. We also found the existence of a strong association between 2B4 expression and loss of $\mathrm{CD}^{+}$iNKT cells. Further, the $2 \mathrm{~B} 4^{+}$iNKT cells of ART-naive cohort positively correlated with HIV viral load and inversely with CD4 count and CD4/CD8 

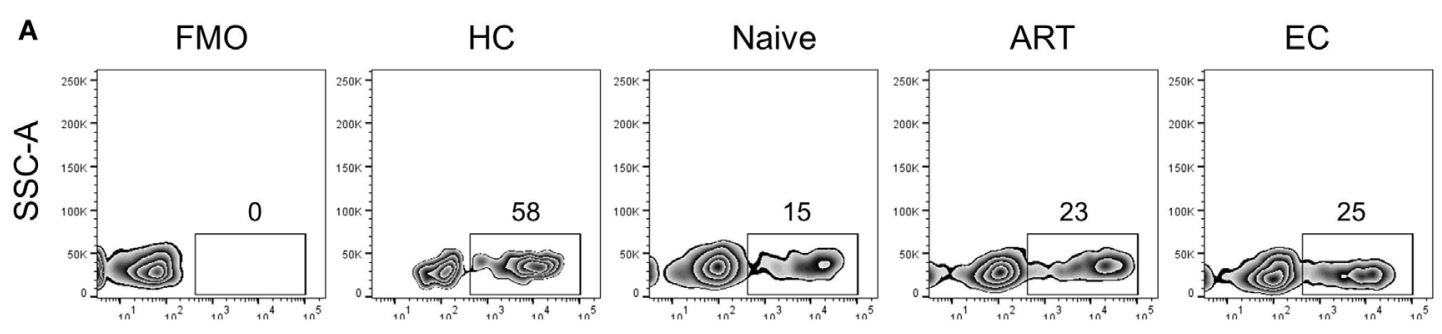

IFN- $\gamma$
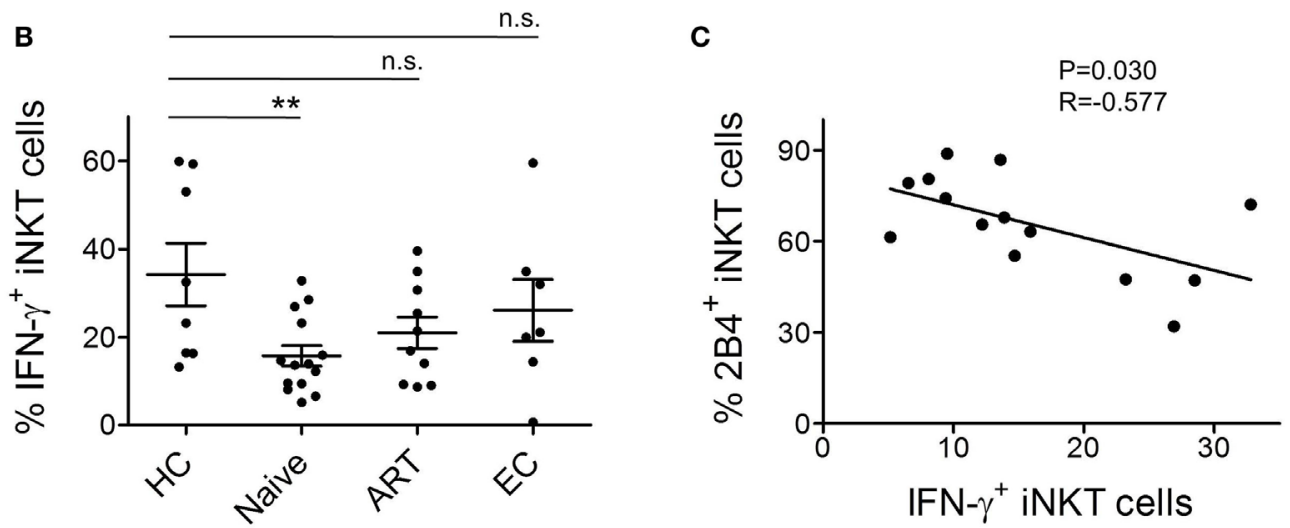

FIGURE 4 | Invariant natural killer T (iNKT) cell production of IFN- $\gamma$ and their association with 2B4 levels. (A) Representative plot from each cohort showing percentage of intracellular IFN- $\gamma$ expression. $\alpha$-GalCer-stimulated peripheral blood mononuclear cells (PBMCs) were surface-labeled with PBS-57 loaded/ CD1d tetramer and CD3 followed by intracellular staining with anti-IFN- $\gamma$ antibody as described in the section "Materials and Methods." iNKT cell-gated population were looked for IFN- $\gamma$ production. (B) Scatter plots show mean percentages of IFN- $\gamma$ production by each cohort HCs $(n=8)$, ART naïve $(n=14)$, ART $(n=10)$, and ECs $(n=6)$. ${ }^{*} P<0.01$ and n.s. stands for non-significant. (C) Plot showing the correlation between $2 \mathrm{~B} 4{ }^{+}$iNKT cells and IFN- $\gamma$ production by ART-naive cohort $(n=14)$.

ratio. Finally, we also found that the iNKT cell phenotypes were functionally impaired in their ability to produce the intracellular anti-viral cytokine IFN- $\gamma$ whose levels inversely correlated with the expression of $2 \mathrm{~B} 4$.

Recent studies have shed light on the anti-viral functions of iNKT cells in HBV, HCV, and HIV infections (2). With regard to HIV, there appears to be a rapid depletion of iNKT cells from the periphery of infected individuals (23). Further, a recent study has shown the early loss of peripheral $\mathrm{CD} 4^{+}$iNKT cells post-HIV infection, and reported a more profound depletion than the classical $\mathrm{CD}^{+} \mathrm{T}$ cells (33). In addition to overall iNKT cell depletion from the periphery, our study has clearly shown the selective depletion of $\mathrm{CD} 4^{+}$iNKT cells as compared to the $\mathrm{CD}^{-}{ }^{-}$subset. It should be noted that $\mathrm{CD} 4^{+}$iNKT cell depletion was associated with increased $\mathrm{CD}^{-}$cell numbers both in HIV-naive and ART-treated individuals, an interesting observation, which has seldom been reported in the past $(22,39)$. Since we did not observe similar effects with respect to ECs, our data suggest that in addition to cell death due to direct infection of $\mathrm{CD} 4^{+}$iNKT cells (40), on-going viral replication and subsequent immune activation (41) could likely play a role in activation-induced cell death (AICD) of activated iNKT cells. One of the limitations of our study is the scarcity of EC samples, which represents a rare population of HIV-infected individuals. Perhaps, the inclusion of more samples from this cohort could have been more informative. Nevertheless, data obtained from our EC study seemingly reflect iNKT cell behavior during HIV infection. We would like to mention that our cohorts comprised different age range and male/female participants that might impact the iNKT cell frequencies. Nonetheless, we succeeded in keeping the age and sex of HC (median age $=39$ ), ART naïve (median age $=38$ ) very much comparable except ART and EC study groups where median age was slightly higher. Since $\mathrm{HC}$ and ART naive represent the two key study groups to describe the effects of HIV on iNKT cell impairments, and hence, a slight age difference with ART and EC may not greatly affect the outcome of our findings. However, a study involving large cohorts of male and female participants indicates that gender and age do not have an impact on iNKT cell frequencies (3).

Initial studies have suggested $2 \mathrm{~B} 4$ as a co-stimulatory receptor to enhance $\mathrm{NK}$ and $\mathrm{CD}^{+} \mathrm{T}$ cell functions $(18,42)$. However, a number of recent studies have shown $2 \mathrm{~B} 4$ to act as both activating as well as inhibitory receptor on NK cells (43) and HCV-specific $\mathrm{CD}^{+} \mathrm{T}$ cells (20). High-level expression of $2 \mathrm{~B} 4$ and other inhibitory receptors has also been observed on exhausted LCMVspecific $\mathrm{CD}^{+} \mathrm{T}$ cells (44) and HIV (45). Interestingly, blockade of 2B4-CD48 interactions has been shown to restore LCMV (46) and human $\mathrm{HBV}$-specific (47) $\mathrm{CD}^{+} \mathrm{T}$ cell effector functions in vitro culture. Furthermore, absence of mouse $2 \mathrm{~B} 4$ has been described to promote NK cell-mediated killing of activated CD8 ${ }^{+}$ 

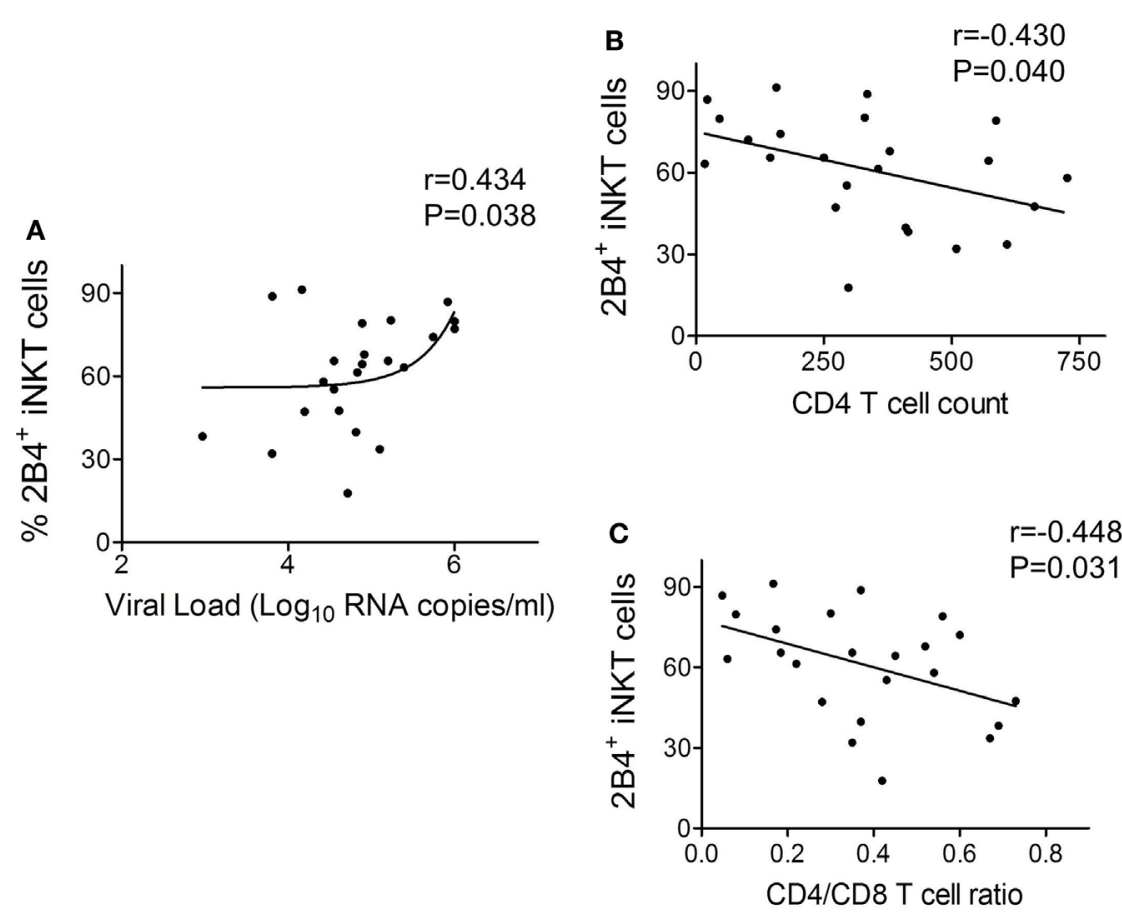

FIGURE 5 | Correlation between frequency of 2B4+ ${ }^{+}$iNKT cells and human immunodeficiency virus (HIV) disease progression. (A) Correlation plot between frequency of 2B4+ iNKT cells versus HIV viral load $(n=23)$ (B) CD4 counts $(n=23)$ and (C) CD4/CD8 ratio $(n=23)$.

T cells (48). These data support our finding that high levels of 2B4 expression contribute to iNKT cells inhibition. Generally, the dual function of 2B4 depends on surface expression level and downstream signaling involving SAP. Although the dual role of 2B4-mediated regulation of virus-specific $\mathrm{CD}^{+} \mathrm{T}$ cells has recently been reported (20), we are not certain if a similar phenomenon also occurs for $\mathrm{CD} 4^{-} \mathrm{iNKT}\left(\mathrm{CD}^{+}\right.$and $\left.\mathrm{DN}\right)$ cells, as this subset too exhibits elevated $2 \mathrm{~B} 4$ expression. Hence, more data are required to address this feature in HIV infection. Nevertheless, the current experimental results point to an inhibitory role for 2B4 expressed on iNKT cells. The strong association between iNKT cell depletion and 2B4 levels, and inverse correlation with IFN- $\gamma$ production clearly supports this hypothesis. Although we did not show the evidence in support, there is a high likelihood that the $\mathrm{CD}^{+}$subset could potentially have been infected with HIV (40) exhibiting high levels of 2B4, and that were selectively depleted during HIV infection. However, these studies require further investigation to completely explore the underlying mechanisms.

Our data further showed an impaired ability of ART-naïve iNKT cells to produce IFN- $\gamma$. ART-treated individuals failed to restore iNKT cell functions despite years of treatment. We were unable to show the expression of IFN- $\gamma^{+}$iNKT cells in standard 6-h in vitro stimulation experiments potentially due to down modulation of $2 \mathrm{~B} 4$ expression post- $\alpha$-GalCer stimulation. One such study has reported this observation where TCR and 2B4 signals were shown to downmodulate $2 \mathrm{~B} 4$ expression on $\mathrm{T}$ cells of HIV-infected individuals (37). Nonetheless, the correlation plot drawn between $2 \mathrm{~B} 4^{+}$iNKT cells and IFN- $\gamma^{+}$iNKT cells clearly indicates an inverse association, supporting the notion that $2 \mathrm{~B} 4$ signaling indeed could lead to suppressed iNKT cell functions. This correlation study is based on data obtained from two separate experiments examining 2B4 expression and intracellular IFN- $\gamma$ production. We were able to include only 14 out of 23 ART-naïve samples representing adequate number of cells to perform both $2 \mathrm{~B} 4$ and IFN- $\gamma$ expression. However, due to fewer number of cells in the remaining nine ART-naïve samples, we could only perform $2 \mathrm{~B} 4$ but not IFN- $\gamma$ expression.

Of note, the clinical significance and relevance of elevated iNKT cell 2B4 expression are clearly supported by the correlation data. The positive correlation with HIV viral load and negative association with $\mathrm{CD} 4$ count and $\mathrm{CD} 4 / \mathrm{CD} 8$ ratio further supports our finding that $2 \mathrm{~B} 4$ indeed could serve as a potential determinant of iNKT cell dysfunction. We speculate that on-going HIV replication in ART-naïve individuals may be one of the factors that drive the enhanced 2B4 expression on iNKT cells hence the functionality, thus warrants further investigation. Further studies are required to understand the mechanisms and signaling events that might trigger iNKT cell inhibition. Potential blockade of 2B4 could provide a clear impetus to understand the factors underlying the restoration of iNKT cell effector functions. Overall, our data have clearly revealed the association of $2 \mathrm{~B} 4$ in iNKT cell impairment during HIV infection.

\section{AUTHOR CONTRIBUTIONS}

AA, AK, and EMS conceived and designed the experiments, FA, ES, and AA carried out experiments and data analysis, and 
documented the findings; YY, HT, and GA selected patient samples and collected the clinical data for patients. AA, FA, EMS, and RS wrote the manuscript; RJ contributed reagents and analysis tools; AK and ML provided critical inputs to the manuscript.

\section{ACKNOWLEDGMENTS}

We are indebted to the HIV-positive individuals and healthy volunteers who participated in this study. We also thank the staff members of the HIV clinic and laboratory. This study was supported by University of Malaya Research Grant (RG50113HTM) of the Health and Translational Medicine Cluster and European Molecular Biology Organization (EMBO) Short-Term Fellowship to AA, Deutsches Zentrum für Infektions forschung (DZIF TTU HIV 04.810 and 04.811). AK was supported by High Impact Research Grant (HIRGA E000001-20001) of the Ministry of Higher Education (MoHE) Malaysia.

\section{REFERENCES}

1. Bendelac A, Savage PB, Teyton L. The biology of NKT cells. Annu Rev Immunol (2007) 25:297-336. doi:10.1146/annurev.immunol.25.022106.141711

2. Juno JA, Keynan Y, Fowke KR. Invariant NKT cells: regulation and function during viral infection. PLoS Pathog (2012) 8(8):e1002838. doi:10.1371/ journal.ppat.1002838

3. Montoya CJ, Pollard D, Martinson J, Kumari K, Wasserfall C, Mulder CB, et al. Characterization of human invariant natural killer $\mathrm{T}$ subsets in health and disease using a novel invariant natural killer T cell-clonotypic monoclonal antibody, 6B11. Immunology (2007) 122(1):1-14. doi:10.1111/j.1365-2567. 2007.02647.x

4. Bienemann K, Iouannidou K, Schoenberg K, Krux F, Reuther S, Feyen $\mathrm{O}$, et al. iNKT cell frequency in peripheral blood of Caucasian children and adolescent: the absolute iNKT cell count is stable from birth to adulthood. Scand JImmunol (2011) 74(4):406-11. doi:10.1111/j.1365-3083. 2011.02591.x

5. Rossjohn J, Pellicci DG, Patel O, Gapin L, Godfrey DI. Recognition of CD1d-restricted antigens by natural killer T cells. Nat Rev Immunol (2012) 12(12):845-57. doi:10.1038/nri3328

6. Gumperz JE, Miyake S, Yamamura T, Brenner MB. Functionally distinct subsets of $\mathrm{CD} 1 \mathrm{~d}$-restricted natural killer $\mathrm{T}$ cells revealed by $\mathrm{CD} 1 \mathrm{~d}$ tetramer staining. J Exp Med (2002) 195(5):625-36. doi:10.1084/jem. 20011786

7. Lee PT, Benlagha K, Teyton L, Bendelac A. Distinct functional lineages of human V(alpha)24 natural killer T cells. J Exp Med (2002) 195(5):637-41. doi:10.1084/jem.20011908

8. Larsson M, Shankar EM, Che KF, Saeidi A, Ellegard R, Barathan M, et al. Molecular signatures of T-cell inhibition in HIV-1 infection. Retrovirology (2013) 10:31. doi:10.1186/1742-4690-10-31

9. Khaitan A, Unutmaz D. Revisiting immune exhaustion during HIV infection. Curr HIV/AIDS Rep (2011) 8(1):4-11. doi:10.1007/s11904-010-0066-0

10. Yamamoto T, Price DA, Casazza JP, Ferrari G, Nason M, Chattopadhyay PK, et al. Surface expression patterns of negative regulatory molecules identify determinants of virus-specific CD8+ T-cell exhaustion in HIV infection. Blood (2011) 117(18):4805-15. doi:10.1182/blood-2010-11-317297

11. Rehr M, Cahenzli J, Haas A, Price DA, Gostick E, Huber M, et al. Emergence of polyfunctional CD8+ $\mathrm{T}$ cells after prolonged suppression of human immunodeficiency virus replication by antiretroviral therapy. J Virol (2008) 82(7):3391-404. doi:10.1128/JVI.02383-07

12. Kassu A, Marcus RA, D’Souza MB, Kelly-McKnight EA, Palmer BE. Suppression of HIV replication by antiretroviral therapy reduces TIM-3 expression on HIV-specific CD8(+) T cells. AIDS Res Hum Retroviruses (2011) 27(1):1-3. doi:10.1089/aid.2010.0156

\section{SUPPLEMENTARY MATERIAL}

The Supplementary Material for this article can be found online at http://journal.frontiersin.org/article/10.3389/fimmu. 2017.00338/full\#supplementary-material.

FIGURE S1 | Gating strategy to identify invariant natural killer T (iNKT) cells and their subsets. Frozen peripheral blood mononuclear cells (PBMCs) were labeled with PBS-57 loaded/CD1d tetramer, CD3, CD4, and live-dead stain (A). Initially, cells were gated on lymphocytes based on SSC-A and FSC-A followed by exclusion of doublet cells using FS-A and FSC-H (B). Singlet cells were gated for live cells by excluding the live-dead cell stain positive population (C). Live cells were gated on $\mathrm{CD}^{+} \mathrm{T}$ cells population (D). CD3 ${ }^{+} \mathrm{T}$ cells were further gated to identify iNKT cells (CD1d tet ${ }^{+}$CD3 ${ }^{+}$cells) $(E)$. iNKT cells were further gated to detect $\mathrm{CD}^{+}$and $\mathrm{CD}^{-}{ }^{-}$subsets (F).

FIGURE S2 | (A) Basal levels of 2B4 expression. Part of the data is adapted from Figure 2, 2B4 expression was re analyzed only in healthy donors. CD3+ $\mathrm{T}$ cell-gated cells were further gated for 2B4 expression on $\mathrm{CD}^{+}$and $\mathrm{CD} 8^{+} \mathrm{T}$ cell populations. (B) Healthy donor data were adapted from Figure 3. CD1d tet ${ }^{+}$ $\mathrm{CD}^{+}{ }^{+}$iNKT cells were gated for 2B4 expression on $\mathrm{CD}^{+}{ }^{+}$and $\mathrm{CD} 44^{-}$subsets.

13. Fromentin R, Bakeman W, Lawani MB, Khoury G, Hartogensis W, DaFonseca S, et al. CD4+ T cells expressing PD-1, TIGIT and LAG-3 contribute to HIV persistence during ART. PLoS Pathog (2016) 12(7):e1005761. doi:10.1371/ journal.ppat.1005761

14. Moll M, Kuylenstierna C, Gonzalez VD, Andersson SK, Bosnjak L, Sonnerborg A, et al. Severe functional impairment and elevated PD-1 expression in CD1drestricted NKT cells retained during chronic HIV-1 infection. Eur J Immunol (2009) 39(3):902-11. doi:10.1002/eji.200838780

15. Brown $\mathrm{MH}$, Boles $\mathrm{K}$, van der Merwe PA, Kumar V, Mathew PA, Barclay AN. 2B4, the natural killer and T cell immunoglobulin superfamily surface protein, is a ligand for CD48. J Exp Med (1998) 188(11):2083-90. doi:10.1084/ jem.188.11.2083

16. Endt J, Eissmann P, Hoffmann SC, Meinke S, Giese T, Watzl C. Modulation of 2B4 (CD244) activity and regulated SAP expression in human NK cells. Eur J Immunol (2007) 37(1):193-8. doi:10.1002/eji.200636341

17. Waggoner SN, Kumar V. Evolving role of $2 \mathrm{~B} 4 / \mathrm{CD} 244$ in $\mathrm{T}$ and NK cell responses during virus infection. Front Immunol (2012) 3:377. doi:10.3389/ fimmu.2012.00377

18. Tangye SG, Cherwinski H, Lanier LL, Phillips JH. 2B4-mediated activation of human natural killer cells. Mol Immunol (2000) 37(9):493-501. doi:10.1016/ S0161-5890(00)00076-6

19. Eissmann P, Beauchamp L, Wooters J, Tilton JC, Long EO, Watzl C. Molecular basis for positive and negative signaling by the natural killer cell receptor 2B4 (CD244). Blood (2005) 105(12):4722-9. doi:10.1182/blood-200409-3796

20. Schlaphoff V, Lunemann S, Suneetha PV, Jaroszewicz J, Grabowski J, Dietz J, et al. Dual function of the NK cell receptor 2B4 (CD244) in the regulation of HCV-specific CD8+ T cells. PLoS Pathog (2011) 7(5):e1002045. doi:10.1371/ journal.ppat.1002045

21. Motsinger A, Haas DW, Stanic AK, Van Kaer L, Joyce S, Unutmaz D. CD1drestricted human natural killer $\mathrm{T}$ cells are highly susceptible to human immunodeficiency virus 1 infection. J Exp Med (2002) 195(7):869-79. doi:10.1084/ jem.20011712

22. Sandberg JK, Fast NM, Palacios EH, Fennelly G, Dobroszycki J, Palumbo $\mathrm{P}$, et al. Selective loss of innate CD4(+) V alpha 24 natural killer T cells in human immunodeficiency virus infection. J Virol (2002) 76(15):7528-34. doi:10.1128/JVI.76.15.7528-7534.2002

23. van der Vliet HJ, von Blomberg BM, Hazenberg MD, Nishi N, Otto SA, van Benthem BH, et al. Selective decrease in circulating V alpha $24+\mathrm{V}$ beta $11+$ NKT cells during HIV type 1 infection. J Immunol (2002) 168(3):1490-5. doi:10.4049/jimmunol.168.3.1490

24. Crowe NY, Godfrey DI, Baxter AG. Natural killer T cells are targets for human immunodeficiency virus infection. Immunology (2003) 108(1):1-2. doi:10.1046/j.1365-2567.2003.01580.x 
25. Kim CH, Johnston B, Butcher EC. Trafficking machinery of NKT cells: shared and differential chemokine receptor expression among $\mathrm{V}$ alpha $24(+) \mathrm{V}$ beta 11(+) NKT cell subsets with distinct cytokine-producing capacity. Blood (2002) 100(1):11-6. doi:10.1182/blood-2001-12-0196

26. van der Vliet HJ, van Vonderen MG, Molling JW, Bontkes HJ, Reijm M, Reiss P, et al. Cutting edge: rapid recovery of NKT cells upon institution of highly active antiretroviral therapy for HIV-1 infection. J Immunol (2006) 177(9):5775-8. doi:10.4049/jimmunol.177.9.5775

27. Snyder-Cappione JE, Loo CP, Carvalho KI, Kuylenstierna C, Deeks SG, Hecht FM, et al. Lower cytokine secretion ex vivo by natural killer $\mathrm{T}$ cells in HIV-infected individuals is associated with higher CD161 expression. AIDS (2009) 23(15):1965-70. doi:10.1097/QAD.0b013e $32832 \mathrm{~b} 5134$

28. Moll M, Snyder-Cappione J, Spotts G, Hecht FM, Sandberg JK, Nixon DF. Expansion of CD1d-restricted NKT cells in patients with primary HIV-1 infection treated with interleukin-2. Blood (2006) 107(8):3081-3. doi:10.1182/ blood-2005-09-3636

29. Vasan S, Poles MA, Horowitz A, Siladji EE, Markowitz M, Tsuji M. Function of NKT cells, potential anti-HIV effector cells, are improved by beginning HAART during acute HIV-1 infection. Int Immunol (2007) 19(8):943-51. doi:10.1093/intimm/dxm055

30. Ansari AW, Bhatnagar N, Dittrich-Breiholz O, Kracht M, Schmidt RE, Heiken H. Host chemokine (C-C motif) ligand-2 (CCL2) is differentially regulated in HIV type 1 (HIV-1)-infected individuals. Int Immunol (2006) 18(10):1443-51. doi:10.1093/intimm/dxl078

31. Ahmad F, Hong HS, Jackel M, Jablonka A, Lu IN, Bhatnagar N, et al. High frequencies of polyfunctional CD8+ NK cells in chronic HIV-1 infection are associated with slower disease progression. J Virol (2014) 88(21):12397-408. doi:10.1128/JVI.01420-14

32. Ansari AW, Temblay JN, Alyahya SH, Ashton-Rickardt PG. Serine protease inhibitor 6 protects iNKT cells from self-inflicted damage. J Immunol (2010) 185(2):877-83. doi:10.4049/jimmunol.1000651

33. Fernandez CS, Kelleher AD, Finlayson R, Godfrey DI, Kent SJ. NKT cell depletion in humans during early HIV infection. Immunol Cell Biol (2014) 92(7):578-90. doi:10.1038/icb.2014.25

34. Petrovas C, Casazza JP, Brenchley JM, Price DA, Gostick E, Adams WC, et al. PD-1 is a regulator of virus-specific CD8+ T cell survival in HIV infection. J Exp Med (2006) 203(10):2281-92. doi:10.1084/jem.20061496

35. Trautmann L, Janbazian L, Chomont N, Said EA, Gimmig S, Bessette B, et al. Upregulation of PD-1 expression on HIV-specific CD8+ T cells leads to reversible immune dysfunction. Nat Med (2006) 12(10):1198-202. doi:10.1038/nm1482

36. Velu V, Titanji K, Zhu B, Husain S, Pladevega A, Lai L, et al. Enhancing SIVspecific immunity in vivo by PD-1 blockade. Nature (2009) 458(7235):206-10. doi:10.1038/nature07662

37. Pacheco Y, McLean AP, Rohrbach J, Porichis F, Kaufmann DE, Kavanagh DG. Simultaneous TCR and CD244 signals induce dynamic downmodulation of CD244 on human antiviral T cells. J Immunol (2013) 191(5):2072-81. doi:10.4049/jimmunol.1300435

38. Day CL, Kaufmann DE, Kiepiela P, Brown JA, Moodley ES, Reddy S, et al. PD-1 expression on HIV-specific T cells is associated with T-cell exhaustion and disease progression. Nature (2006) 443(7109):350-4. doi:10.1038/ nature 05115

39. Yang OO, Wilson SB, Hultin LE, Detels R, Hultin PM, Ibarrondo FJ, et al. Delayed reconstitution of CD4+ iNKT cells after effective HIV type 1 therapy. AIDS Res Hum Retroviruses (2007) 23(7):913-22. doi:10.1089/aid. 2006.0253

40. Fleuridor R, Wilson B, Hou R, Landay A, Kessler H, Al-Harthi L. CD1d-restricted natural killer $\mathrm{T}$ cells are potent targets for human immunodeficiency virus infection. Immunology (2003) 108(1):3-9. doi:10.1046/j.1365-2567.2003.01560.x

41. Bachle SM, Malone DF, Buggert M, Karlsson AC, Isberg PE, Biague AJ, et al. Elevated levels of invariant natural killer T-cell and natural killer cell activation correlate with disease progression in HIV-1 and HIV-2 infections. AIDS (2016) 30(11):1713-22. doi:10.1097/QAD.0000000000001147

42. Nakajima H, Cella M, Langen H, Friedlein A, Colonna M. Activating interactions in human $\mathrm{NK}$ cell recognition: the role of 2B4-CD48. Eur J Immunol (1999) 29(5):1676-83. doi:10.1002/(SICI)1521-4141(199905) 29:05<1676:AID-IMMU1676>3.0.CO;2-Y

43. Chlewicki LK, Velikovsky CA, Balakrishnan V, Mariuzza RA, Kumar V. Molecular basis of the dual functions of 2B4 (CD244). JImmunol (2008) 180(12):8159-67. doi:10.4049/jimmunol.180.12.8159

44. Wherry EJ, Ha SJ, Kaech SM, Haining WN, Sarkar S, Kalia V, et al. Molecular signature of CD8+ T cell exhaustion during chronic viral infection. Immunity (2007) 27(4):670-84. doi:10.1016/j.immuni.2007.09.006

45. Aldy KN, Horton NC, Mathew PA, Mathew SO. 2B4+ CD8+ T cells play an inhibitory role against constrained HIV epitopes. Biochem Biophys Res Commun (2011) 405(3):503-7. doi:10.1016/j.bbrc.2011.01.062

46. Blackburn SD, Shin H, Haining WN, Zou T, Workman CJ, Polley A, et al. Coregulation of CD8+ T cell exhaustion by multiple inhibitory receptors during chronic viral infection. Nat Immunol (2009) 10(1):29-37. doi:10.1038/ ni.1679

47. Raziorrouh B, Schraut W, Gerlach T, Nowack D, Gruner NH, Ulsenheimer A, et al. The immunoregulatory role of CD244 in chronic hepatitis B infection and its inhibitory potential on virus-specific CD8+ T-cell function. Hepatology (2010) 52(6):1934-47. doi:10.1002/hep.23936

48. Waggoner SN, Taniguchi RT, Mathew PA, Kumar V, Welsh RM. Absence of mouse 2B4 promotes NK cell-mediated killing of activated CD8+ T cells, leading to prolonged viral persistence and altered pathogenesis. J Clin Invest (2010) 120(6):1925-38. doi:10.1172/JCI4126441264

Conflict of Interest Statement: The authors declare that the research was conducted in the absence of any commercial or financial relationships that could be construed as a potential conflict of interest.

Copyright (c) 2017 Ahmad, Shankar, Yong, Tan, Ahrenstorf, Jacobs, Larsson, Schmidt, Kamarulzaman and Ansari. This is an open-access article distributed under the terms of the Creative Commons Attribution License (CC BY). The use, distribution or reproduction in other forums is permitted, provided the original author(s) or licensor are credited and that the original publication in this journal is cited, in accordance with accepted academic practice. No use, distribution or reproduction is permitted which does not comply with these terms. 